\title{
Enhancement of pork quality from pigs fed feeds supplemented with antioxidants containing defatted sesame dregs and dried barley leaves
}

\author{
Myung-Hwa Kang ${ }^{1}$, Kwan-Sik Min ${ }^{2,}$, Takayuki Shibamoto ${ }^{3,}$, \\ ${ }^{1}$ Department of Food and Nutrition, Hoseo University, Asan 336-795, Korea \\ ${ }^{2}$ Graduate School of Bio, \& Information Technology, Institute of Genetic Engineering, Hankyong National University, Ansung, Korea \\ ${ }^{3}$ Department of Environmental Toxicology, University of California, Davis, CA, 95616, USA
}

\section{Email address:}

tshibamoto@ucdavis.edu (T. Shibamoto), ksmin@hknu.ac.kr (K.-S Min)

\section{To cite this article:}

Myung-Hwa Kang, Kwan-Sik Min, Takayuki Shibamoto. Enhancement of Pork Quality from Pigs Fed Feeds Supplemented with Antioxidants Containing Defatted Sesame Dregs and Dried Barley Leaves. International Journal of Nutrition and Food Sciences. Vol. 2, No. 6, 2013, pp. 301-036. doi: 10.11648/j.ijnfs.20130206.16

\begin{abstract}
Moisture content, crude fat content, fatty acid composition, $\mathrm{pH}$, water-holding capacity, Warner-Bratzler shear force (WBsf), and meat color were measured to evaluate the quality of meats from pigs fed a special diet of feed supplemented with defatted sesame dregs and barley leaf (DSBL). Slight differences in moisture content, water-holding capacity, color, and $\mathrm{pH}$ were seen in meats from the pigs fed the special diet. However, the DSBL $(5 \%$ each of defatted sesame dregs and barley leaf in feed) supplemented diet considerably improved pork quality as evaluated using WBsf values, suggesting that these supplements contain antioxidants. Crude fat content in meats from the pigs decreased with increased percentages of DSBL in the diets. Generally, compositional decrease was observed in margaric, stearic and linoleic acids in the meats from the pigs fed the special diet. The results suggest that supplementing antioxidants in feeds improve pork quality.
\end{abstract}

Keywords: Antioxidants, Barley Leaf, Defatted Sesame Dregs, Fatty Acids, Pork Quality

\section{Introduction}

Food quality depends on various factors, including taste, flavor, color, and texture as well as nutritional content. In the case of meats, consumer preference is influenced by the fat content in muscle and its water-holding capacity in addition to the factors mentioned above. Above all, the quality of meat products depends on the occurrence of lipid peroxidation, which plays an important role in meat quality [1]. Therefore, synthetic antioxidants, such as BHT, have been commonly used in meats and meat products to prevent lipid oxidation in order to preserve quality. However, synthetic chemicals used in food products have also been found to produce some adverse effects on human health [2].

Consumers have begun to demand that food manufacturers use safe and natural supplements to improve meat quality [3]. Consequently, food research has come to be aimed at developing ways to improve meat quality using natural antioxidants. For example, recent reports have demonstrated that the quality of broiler meat was improved by using feed containing natural antioxidants, $\alpha$-lipoic acid and $\alpha$-tocopherol [4]. Another study reported that a carnosine supplemented diet improved the antioxidant capacity and meat quality of pork [5].

In the present study, the role of an antioxidant-containing feed supplement, a mixture of defatted sesame dregs and barley leaves, in enhancing the quality of pork was investigated. Defatted sesame dregs were used because they have been reported to contain the antioxidant sesaminol glucoside and had been used as feed for livestock to improve meat quality [6]. Young green barley leaves were used because they also contain the potent antioxidants saponarin and lutonarin, the antioxidant activity of which is comparable to that of the well-known natural antioxidant, $\alpha$-tocopherol [7]. 


\section{Materials and Methods}

\subsection{Chemicals and Reagents}

Methyl esters of palmitic (C16:0), margaric (C17:0), stearic (C18:0), oleic (C18:1), linoleic (C18:2), and gondoic (C20:1) acids were purchased from Sigma Co. (St. Louis, MO, USA). All reagents were the highest available grade and were bought from reliable commercial sources.

\subsection{Defatted Sesame Dregs and Barley Leaves}

Defatted sesame dregs (Sesamum L.,) were prepared from raw sesame seeds (obtained from a local market in Masan, South Korea) by roasting for $15 \mathrm{~min}$ at $230^{\circ} \mathrm{C}$, and then defatting by a previously reported method [8]. Barley leaves (Hordeum vulgare L.,) were cultivated in a greenhouse until they reached a height of $25 \mathrm{~cm}$. After pruning ( 5 $\mathrm{cm}$ height), the barley leaves were dried using a dryer at $45^{\circ} \mathrm{C}$.

\subsection{Animal and Diets}

Thirty castrated male pigs (Landrace; 53 - 63 days old) were obtained from Jinwang Farm, Seungnam, Chungnam, South Korea. The experimental pigs were randomly divided into five groups $(n=6)$ and fed diets prepared from standard diet, Dodram concentrated feed, containing various levels of defatted sesame dregs and dried barley leaves (DSBL) during their general growth period. The details of the diets are shown in Table 1. The control group was fed the feed without DSBL.

Table 1. Various types of pig feed supplemented diets fed to each group

\begin{tabular}{ll}
\hline Group name & Pig feed supplemented diets \\
\hline Control & Standard diet-dodram feed \\
DSBL 2.5 & $2.5 \%$ Defatted sesame dreg $+2.5 \%$ Barley leaves \\
DSBL 5 & $5.0 \%$ Defatted sesame dreg $+5.0 \%$ Barley leaves \\
DSBL 10 & $10.0 \%$ Defatted sesame dreg $+10.0 \%$ Barley leaves \\
DSBL 20 & $20.0 \%$ Defatted sesame dreg $+20.0 \%$ Barley leaves \\
\hline
\end{tabular}

After 3 months, the treated pigs were fasted overnight and slaughtered at SAJO Co., Jiksan, Cheonan, Korea. All meat samples were selected from the same area of the backbone (3th and 5th lumbar vertebrae). The meat samples prepared were vacuum-packed and stored at $4{ }^{\circ} \mathrm{C}$ until used.

\subsection{Measurement of Meat Color}

After the samples prepared in the above section (2.3) were stored at $4^{\circ} \mathrm{C}$ for $24 \mathrm{~h}$, meat color was measured using a colorimeter (CR-300, Minolta Co.,) according to a previously reported method [9]. Value L is a measurement of brightness. Values $a$ and $b$ indicate redness and yellowness, respectively. Tiles $(\mathrm{Y}=92.40, \mathrm{X}=0.3136$, and $\mathrm{y}=0.3196)$ were used as a white standard board. Measurements were repeated three times.

\subsection{Measurement of Moisture, $\mathrm{pH}$, and Water-holding Capacity}

Moisture content was determined according to the method described in the AOAC [10]. Briefly, a meat sample (see section 2.3) was homogenized, and then $2 \mathrm{~g}$ of the homogenized meat sample was placed in an oven at $100^{\circ} \mathrm{C}$ until a constant weight was achieved, after which the dried meat was allowed to stand in a desiccator until it cooled to room temperature. The moisture content of the meats was determined using a previously published method [4].

$\mathrm{pH}$ was measured using a previously reported method [11]. Briefly, a portable needle-tipped combination electrode (NWKbinar pH-K21, Germany) was placed in the center of the muscle between the 3th and 4th lumber vertebrae and proximal end of the biceps femoris at approximately $30 \mathrm{~min}$ postmortem.

Water-holding capacity was measured according to a previously reported method [12]. Meat samples were prepared for measurement of water-holding capacity as follows: After the stringy and fat parts were removed from the meat sample prepared as described in section $2.3,0.5 \mathrm{~g}$ samples were heated for $20 \mathrm{~min}$ at $80^{\circ} \mathrm{C}$. The samples were allowed to cool at room temperature, and then centrifuged at 2,000 rpm for $10 \mathrm{~min}$.

\subsection{Analysis of Crude Fat}

The crude fat content was determined using a previously published method [4]. Briefly, dried meat samples (1 g) prepared by the method described above in section 2.5 were homogenized and then extracted with $n$-hexane $(10 \mathrm{ml})$ using a soxlhet extractor. The solvent was removed from the extract under a purified nitrogen stream.

\subsection{Determination of Fatty Acids Composition}

Identification of fatty acids as methyl ester derivatives was conducted by comparison with the gas chromatographic retention and by the mass spectral fragmentation pattern of each component with those of authentic compounds.

The sample preparations for fatty acids analysis in the meat samples were conducted by a previously reported method [13]. Briefly, after a meat sample $(50 \mathrm{mg})$ prepared by the method described above in section 2.5 and $3 \mathrm{mg}$ of heptadecanoic acid (internal standard) were placed in a tube with a teflon-lined cap, $17 \mathrm{mg}$ of refined olive oil and a 2.1 $\mathrm{mL}$ mixture of methanol/benzene/2,2dimethoxypropane/6 $\mathrm{N} \mathrm{H}_{2} \mathrm{SO}_{4}(37 / 20 / 5 / 2 ; \mathrm{v} / \mathrm{v})$ were added. Volume of the sample solution was adjusted to $5 \mathrm{~mL}$ by the addition of heptane and then incubated in a water bath at $80^{\circ} \mathrm{C}$ for $2 \mathrm{~h}$. After the reaction mixture cooled to room temperature, the tube was shaken and allowed to stand until it separated into two layers.

The upper layer of the reaction mixture was analyzed by an Agilent model 6890 gas chromatograph (GC) equipped with a $30 \mathrm{~m} \times 0.25 \mathrm{~mm}$ i.d. $\left(\mathrm{d}_{\mathrm{f}}=0.5 \mu \mathrm{m}\right)$ DB-5 bondedphase fused silica capillary column (Agilent, Folsom, CA) 
and interfaced to an Agilent 9571A mass selective detector (GC/MS) operated at MS ionization voltage of $70 \mathrm{eV}$. The helium carrier gas flow rate was $1.0 \mathrm{~mL} / \mathrm{min}$ at a splitless injection. The injector and detector temperatures were $260^{\circ} \mathrm{C}$ and $280^{\circ} \mathrm{C}$, respectively. The oven temperature was held at $50^{\circ} \mathrm{C}$ and then programmed to $290^{\circ} \mathrm{C}$ at $5^{\circ} \mathrm{C} / \mathrm{min}$ and held for $20 \mathrm{~min}$.

\subsection{Measurement of Warner-Bratzler Shear Force (WBsf)}

Meat samples (thickness; $2.5 \mathrm{~cm}, 500 \mathrm{~g}$ ) were put in plastic bags, and cooked in a water bath $\left(70^{\circ} \mathrm{C}\right)$ until the temperature of the middle part of the sample reached $70^{\circ} \mathrm{C}$ then cooled for $30 \mathrm{~min}$ in flowing water $\left(20^{\circ} \mathrm{C}\right)$. Circular cores $(1.27 \mathrm{~cm})$ were used to determine the WBsf of the cooked meat $(2.5 \mathrm{~cm}$ thick). Eight cores were made for each sample, and the peak force was determined using an Instron Model 4465 (Instron Corp., UK) with a $50 \mathrm{~kg}$ load cell and head speed at $200 \mathrm{~mm} / \mathrm{min}$.

\subsection{Statistical Analysis}

All results are expressed by mean \pm standard deviation ( $n$ $=6$ ). ASAS Program version 9.1 (SAS, 2004) was used to conduct Duncan's multiple range test, at $\mathrm{p}<0.05$.

\section{Results and Discussion}

\subsection{Meat Color}

Table 2 shows the color-brightness of meats from the control and treated groups. As mentioned above, colorbrightness is the most important factor for meat palatability and consumer preference. The DSBL 5 group exhibited the highest L-value (a measure of brightness), while the lowest L-value was observed in the DSBL 20 group. However, only slight differences in color were observed between meats obtained from the treated groups vs. the control group. While the value- $a$ (redness) of meats from the treated groups were higher than that of the control group, the difference was not significant. Value- $b$ (yellowness) was also higher in the treated groups (except the DSBL 20 group) than in the control group. These results are consistent with a previous report that demonstrated increased redness of pork meat taken from pigs fed with onion peel [14]. Another study reported that values- $a$ and $-b$ in the meat of ducks fed ginseng increased during storage, whereas the color-brightness decreased [15]. These results were generally consistent with those found in the present study, suggesting that DSBL diets improve meat's appearance.

\subsection{Moisture Content, pH, and Water-holding Capacity}

There was no appreciable difference in moisture content, $\mathrm{pH}$, and water-holding capacity among the meat samples from the five groups, suggesting that the DSBL supplement did not influence these factors significantly. The moisture content ranged from $73.95 \pm 0.06 \%$ (DSBL 2.5) to $74.84 \pm$
$0.47 \%$ (DSBL 20). The $\mathrm{pH}$ ranged from $5.52 \pm 0.10$ (DSBL 5) to $5.57 \pm 0.04$ (DSBL 20). The water-holding capacity ranged from $53.24 \pm 1.00 \%$ (DSBL 20) to $55.60 \pm 0.67 \%$ (DSBL 10).

It is generally known that $\mathrm{pH}$ affects the freshness, water-holding capacity, and color of meat [16]. For example, high $\mathrm{pH}$ is known to play a role in the changes of sarcoplasmic protein and myofibrils in pork after pigs were slaughtered [17]. Water-holding capacity is influenced by factors such as color and $\mathrm{pH}$ [18]. A previous study showed that no significant changes in the water-holding capacity of meat from pigs fed ginseng was observed until the fifth day of storage, but after that was followed by great increases from the 10th day of storage on [15]. Another study reported that onion supplementation increased the waterholding capacity of duck meat [19].

However, the results of the present study indicate that these factors did not influence each other and did not significantly contribute to the meat quality.

\subsection{Crude Fat Content and Fatty Acid Composition}

Figure 1 shows the crude fat content in the five groups. Different superscripts within the same row are significantly different $(\mathrm{p}<0.05)$. The results from each group were considerably different, ranging from $0.60 \pm 0.04 \%$ (DSBL $20)$ to $1.46 \pm 0.56 \%$ (Control). The results did not show dose response activity but it is obvious that the supplementation of DSBL reduced the fat content of meat. In particular, nearly $60 \%$ reduction of fat content was observed in the meat from the DSBL 20 group. A previous report has also demonstrated that dietary supplementation with onion reduced the fat content in duck meat [19]. It is known that some, in particular cardiovascular, diseases may be caused by certain fats [20]. Therefore, consumers recently have tended to choose a low fat diet, and much researches have been conducted to find ways to reduce the fat content in meats [21]. It should also be noted, however, that reduction of fat content may sacrifice the formation of preferable flavor chemicals because fat is one of the important precursors of flavor chemicals [22]. Also, some fatty acids, such as $\omega-3$ fatty acids have been known to possess beneficial effects on vascular function [23], suggesting that composition of the fatty acids in meat is important to understand to evaluate the role of fats in meat quality [24].

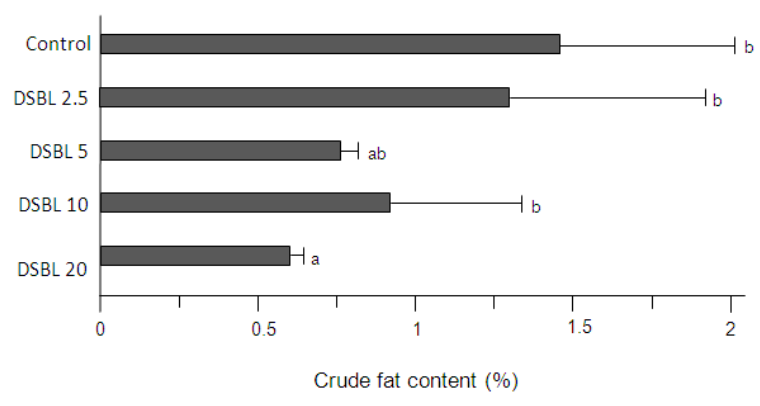

Figure 1. The crude fat contents found in the 5 test groups. 
The fatty acid composition of the meat samples in this study is shown in Table 3. Of the 6 fatty acids ( 3 saturated and 3 unsaturated) found, oleic acid (C18:1) had the greatest quantities, ranging from $36.43 \pm 5.42 \%$ (control) to $46.26 \pm 0.45 \%$ (DSBL 10), followed by palmitic acid (C16:0) ranging from $22.93 \pm 1.05 \%$ (DSBL 2.5) to 25.30 $\pm 1.31 \%$ (DSBL 10), linoleic acid (CC18:2) ranging from $13.39 \pm 5.84 \%$ (DSBL 5) to $20.40 \pm 2.52 \%$ (control), stearic acid (C18:0) ranging from $13.20 \pm 0.99 \%$ (DSBL 10) to control (16.23 $\pm 1.02 \%)$, and margaric acid
(C17:0)/gondoic acid (C20:0) ranging from $2.49 \pm 0.05 \%$ (control) $/ 0.04 \pm 0.00 \%$ (control) to $2.61 \pm 0.09 \%$ (DSBL $2.5) / 2.97 \pm 1.05 \%$ (DSBL 10). Generally, a compositional decrease was observed in unsaturated margaric and stearic acids in the meat samples from the treated groups. The addition of DSBL 10 decreased the amounts of margaric and stearic acids detected by $56.6 \%$ and $18.7 \%$, respectively. The addition of DBSL 2.5 increased the amount of margaric acid found by $5 \%$ compared with the control (Table 3).

Table 2. Color of meats from control and treated groups.

\begin{tabular}{cccc}
\hline Group name & L & $\boldsymbol{a}$ & $\boldsymbol{b}$ \\
\hline Control & $57.68 \pm 4.33^{\mathrm{NS}}$ & $7.89 \pm 0.97^{\mathrm{NS}}$ & $4.29 \pm 0.97^{\mathrm{NS}}$ \\
DSBL 2.5 & $56.73 \pm 3.37$ & $8.38 \pm 1.24$ & $4.90 \pm 1.11$ \\
DSBL 5 & $59.36 \pm 5.60$ & $8.33 \pm 0.96$ & $4.69 \pm 1.92$ \\
DSBL 10 & $56.07 \pm 2.11$ & $8.81 \pm 1.60$ & $5.06 \pm 1.11$ \\
DSBL 20 & $52.92 \pm 0.63$ & $8.24 \pm 0.79$ & $3.96 \pm 0.65$ \\
\hline
\end{tabular}

NS: not significant

Table 3. Fatty acid compositions of meat from control and treated groups.

\begin{tabular}{ccccccc}
\hline \multicolumn{7}{c}{ Composition of acids (\%) } \\
\hline Group name & Palmitic (16:0) & Margaric (17:0) & Stearic (18:0) & Oleic (18:1) & Linoleic (18:2) & Gondoic (20:1) \\
\hline Control & $24.40 \pm 3.21^{\mathrm{NS}}$ & $2.49 \pm 0.05^{\mathrm{c}}$ & $16.23 \pm 1.02^{\mathrm{NS}}$ & $36.43 \pm 5.42^{\mathrm{b}}$ & $20.40 \pm 2.52^{\mathrm{NS}}$ & $0.04 \pm 0.00^{\mathrm{d}}$ \\
DSBL 2.5 & $22.93 \pm 1.05$ & $2.61 \pm 0.09^{\mathrm{c}}$ & $13.78 \pm 1.58$ & $39.76 \pm 6.52^{\mathrm{b}}$ & $19.14 \pm 2.47$ & $1.77 \pm 0.57^{\mathrm{c}}$ \\
DSBL 5.0 & $24.27 \pm 2.39$ & $1.93 \pm 1.1^{\mathrm{b}}$ & $14.30 \pm 0.70$ & $40.95 \pm 5.94^{\mathrm{b}}$ & $13.39 \pm 5.84$ & $2.55 \pm 1.05^{\mathrm{b}}$ \\
DSBL 10.0 & $25.30 \pm 1.31$ & $1.08 \pm 0.13^{\mathrm{a}}$ & $13.20 \pm 0.99$ & $46.29 \pm 0.45^{\mathrm{a}}$ & $15.47 \pm 5.49$ & $2.97 \pm 1.05^{\mathrm{a}}$ \\
DSBL 20.0 & $24.12 \pm 1.43$ & $1.78 \pm 0.46^{\mathrm{b}}$ & $14.53 \pm 1.63$ & $41.09 \pm 3.04^{\mathrm{b}}$ & $15.83 \pm 4.29$ & $2.65 \pm 2.50^{\mathrm{a}}$ \\
\hline
\end{tabular}

NS: not significant.

Different superscripts within the same row are significantly different $(\mathrm{p}<0.05)$.

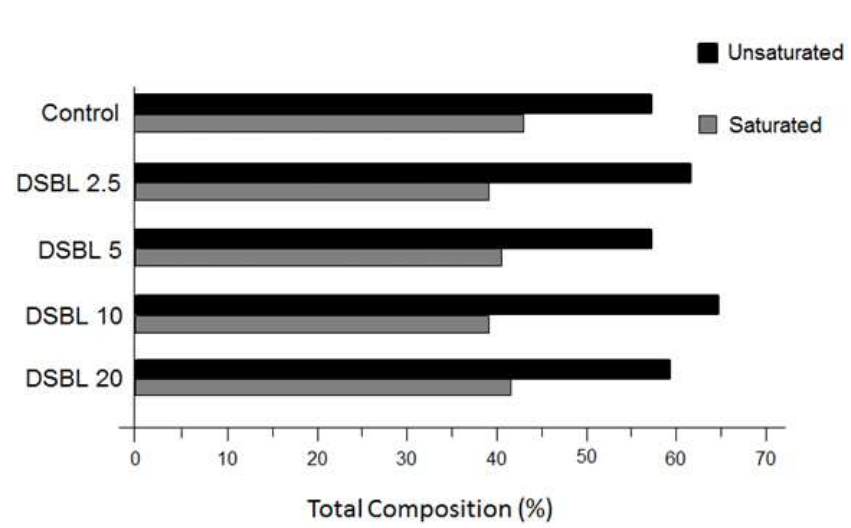

Figure 2. The total compositions of unsaturated fatty acids (oleic, linoleic, and gondoic) and saturated fatty acids (palmitic margaric, and stearic) in the meats from the control and the treated groups.

Figure 2 shows the total compositions of unsaturated fatty acids (oleic, linoleic, and gondoic) and saturated fatty acids (palmitic, margaric, and stearic) in the meat samples. The total proportion of saturated fatty acids was less in the meat samples from the treated groups than the control group, whereas that of unsaturated fatty acids was greater in the meat samples from the treated groups. It is reported that unsaturated fatty acids can help lower harmful cholesterol while not changing the HDL-cholesterol content [25]. From the nutritional point of view, it is commonly recognized that the higher the composition of unsaturated fatty acids the better the quality of the meat [26]. Therefore, the DSBL10 supplement had the best effect on meat quality. The results from these previous reports and the present study were consistent and suggest that DSBL-supplemented diets improve the nutritional quality of pork.

\subsection{Warner-Bratzler Shear Force (WBsf)}

WBsf has commonly been used to evaluate the tenderness of meats [27]. The results of the WBsf test are shown in Figure 3. The values of WBsf of meats from treated groups ranged from $2.33 \pm 0.70 \mathrm{~kg} / 0.5 \mathrm{inch}^{2}$ (DSBL 2.5 ) to $3.19 \pm 0.46 \mathrm{~kg} / 0.5 \mathrm{inch}^{2}$ (DSBL 5). The meats from the DSBL 2.5 and 20 groups exhibited the greatest tenderness. Conversely, the meat from DSBL 5 group showed slightly lower tenderness than the meat from the control group. These results indicate that a DBSL diet supplement influences the tenderness of meats. Generally, 
the lower the WBsf value the more tender the meat [27]. Feeds containing antioxidants, such as vitamins $\mathrm{C}$ and $\mathrm{E}$, have been known to improve meat quality. For example, a recent report demonstrated that daily administration of $1,000 \mathrm{IU}$ of vitamin E effectively decreased WBsf value and that the tenderness of the beef was improved [28]. It is proposed, therefore, that the WBsf value of meat is associated with the presence of antioxidants in feeds [15].

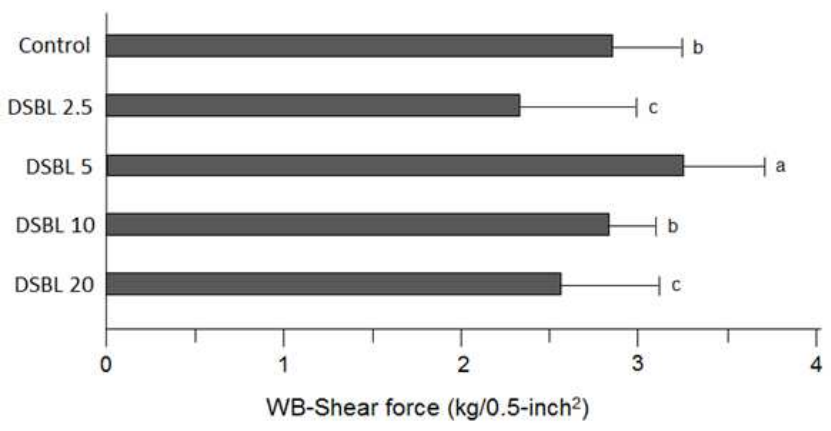

Figure 3. The results of the WB-shear force test. Small letters are indicate significance [?] levels completed by Duncan's multiple range test at $p=$ 0.05 after the ANOVA analysis.

Antioxidants, such as sesame oil, are well known to have health benefits $[8,29]$. For example, one previous study reported that defatted sesame dregs exhibited potent beneficial effects on hypercholesterolemic rabbits [30]. Furthermore there have been many reports on the antioxidant activity of barley leaf essences [31]. Therefore, it is reasonable to conclude that the antioxidants in the DSBL diet could improve the quality of meat from pigs that were fed such a diet.

\section{Conclusion}

The direct addition of certain chemicals, such as antioxidants, to meat products has been used to improve their quality. However, improving meat quality by feeding livestock feed modified with some supplements has not been tried extensively yet. In the present study, it was found that feeds supplemented with defatted sesame dregs and barley leaves containing antioxidants enhanced pork quality with increasing the levels of unsaturated oleic and gondoic acids. Overall, factors affecting meat quality, including fat content, fatty acids composition, color, and WBsf, were improved by the diets prepared in the present study. The results obtained in the present study indicate that diet supplements can indirectly improve the quality of pork.

\section{References}

[1] Kanner, J., 1994. Oxidative processes in meat and meat products: Quality implications. Meat Sci. 36, 169-189.

[2] Shahidi, F., Janita, P., Wanasundara, P.D., 1992. Phenolic antioxidants. Crit. Rev. Food Sci.Nutr.32, 67-103.
[3] Hayes, J.E., Stepanyan, V., Allen, P., O’Grady, M.N., O'Brien, N.M., Kerry, J.P., 2009. The effect of lutein, sesamol, ellagic acid and olive leaf extract on lipid oxidation and oxymyoglobin oxidation in bovine and porcine muscle model systems. Meat Sci.83, 201-208.

[4] Yasin, M., Asghar, A., Anjum, F.M., Butt, M.S., Khan, M.I., Arshad, M.S., Shahid, M., El-Ghrab, A.H., Shibamoto, T., 2012. Oxidative stability enhancement of broiler bird meats with a-lipoic acid and a-tocopherol acetate supplemented feed. Food Chem. 131, 768-773.

[5] Ma, X.Y., Jiang, Z.Y., Lin, Y.C., Zheng, C.T., Zhou, G.L., 2010. Dietary supplementation with carnosine improves antioxidant capacity and meat quality of finishing pigs. J. Animal Physiol. Animal Nutr., 94, e286-295.

[6] Kang, M.H., Ryu, S.N., Bang, J.K., Kang, C.W., Kim, D.W., Lee, B.H., 2000. Physicochemical properties of introduced and domestic sesame seeds. J. Korean Food Sci. Nutr.29, $188-192$.

[7] Benedet, J.A., Umeda, H., Shibamoto, T., 2007. Antioxidant activity of flavonoids isolated from young green barley leaves toward biological lipid samples. J. Agric. Food Chem. $55,5499-5504$.

[8] Lee, S.-C., Jeong, S.-M., Kim, S.-Y., Nam, K. C., Ahn, D.U., 2005. Effect of far-infrared irradiation on the antioxidant activity of defatted sesame meal extracts. J. Agri. Food Chem. 53, 1495-1498.

[9] Mancini, R.A., Hunt, M.C., 2005. Current research in meat color. Meat Sci. 71, 100-121.

[10] AOAC (Association of Official Analytical Chemists). 2002. Official Method of Analysis. 17th ed. Gaithersburg, MD.

[11] Hwang, I.H., Park, B.Y., Cho, S.H., Kim, M.J., Lee, J.M., 2004. Effects of pre-slaughter fasting and chiller ageing on objective meat quality in longissimus dorsi, biceps femoris, and triceps brachli muscles of Korean native black pigs. J. Animal Sci. Technol. 46, 405-414.

[12] Honikel, K.O., Hamm, R., 1994. Measurement of waterholding capacity and juiciness. In: Advances in Meat Research. Vol. 9. Quality Attributes and Their Measurement in Meat, Poultry and Fish Products (ed. A.M. Pearson and T.R. Dutson). Blackie Academic and Professional. London, UK: pp. 125-161.

[13] Garces, R., Mancha, M., 1993. One-step lipid extraction and fatty acid methyl esters preparation from fresh plant tissues was conducted. Anal. Biochem. 211, 139-143.

[14] Park, G.B., Hur, S.J., Lee, J.I., Kim, T.H., Ha, Y.L., Joo, S.T., 2000. Effects of onion peel components on lipid oxidation and the changes of color in press ham. Korean J. Food Sci. Animal Resour. 20, 93-100.

[15] Yoo, Y.M., Ahn, J.N., Cea, H.S., Park, B.Y., Kim, J.H., Lee, J.M., Kim, Y.K., Park, H.K., 2004. Characteristic of pork quality during storage fed with ginseng by-products. Korean J. Food Sci. Animal Resour. 24, 37-43.

[16] Miller, W.O., Saffle, R.L., Zirkle, S.S., 1968. Factors which influence the water- holding capacity of various types of meat. J. Food Technol. 22, 1139-1144.

[17] Femaandez, X., Forslid, A., Tomberg, E., 1994. The effect of high post-mortem temperature on the development of 
pale, soft and exudative pork: interaction with ultimate $\mathrm{pH}$. Meat Sci. 37, 133-147.

[18] Van Laack, R.L.J.M., Kauffman, R.G., Sybesma, W., Smulders, F.J.M., Eikelenboom, G., Pinheiro, J.C., 1994. Is color brightness (L-value) a reliable indicator of waterholding capacity in porcine muscle? Meat Sci. 38, 193-201.

[19] Song, Y.M., Jin, S.K., Kim, I.S., Cho, Y.C., Kim, H.Y., Hah, K.H., Nam, K.Y., 2004. Effects of dietary onion supplementation on the physicochemical properties of duck meat. Korean J. Food Sci. Animal Resour. 24, 66-72.

[20] Schwingshackl, L., Hoffmann, G., 2012. Monounsaturated fatty acids and risk of cardiovascular disease: synopsis of the evidence available from systematic reviews and metaanalyses. Nutrients 4, 1989-2007.

[21] Brewer, M.S., 2012. Reducing the fat content in ground beef without sacrificing quality: a review. Meat Sci. 91, 385-395.

[22] Ohnishi, S., Shibamoto, T., 1984. Volatile compounds from heated beef fat and beef fat with glycine. J. Agric. Food Chem. 332, 987-992.

[23] Lovegrove, J.A., Griffin, B.A., 2013. The acute and longterm effects of dietary fatty acids on vascular function in health and disease. Curr. Opin. Clin. Nutr. Metab. Care 16, $162-167$.

[24] Wood, J.D., Enser, M., Fisher, A.V., Nute, G.R., Richardson, R.I., Sheard, P.R., 1999. Manipulating meat quality and composition. Proc. Nutr. Soc. 58, 363-370.
[25] Guillevic, M., Kouba, M., Mourot, J., 2009. Effect of a linseed diet on lipid composition, lipid peroxidation and consumer evaluation of French and cooked pork meats. Meat Sci.81, 612-618.

[26] Vafeiadou, K., Weech, M., Sharma, V., Yaqoob, P., Todd, S., Williams, C.M., Jackson, K.G., Lovegrove, J.A., 2012. A review of the evidence for the effects of total dietary fat, saturated, monounsaturated and $n-6$ polyunsaturated fatty acids on vascular function, endothelial progenitor cells and microparticles. Brit. J. Nutr. 107, 303-324.

[27] Wheeler, T.L., Shackelford, S.D., Johnson, L.P., Miller, M.F., Miller, R.K., Koohmaraie, M., 1997. A comparison of Warner-Bratzler shear force assessment within and among institutions. J. Animal Sci. 75, 2423-2432.

[28] Camagey, K.M., Huff-Lonergan, E.J., Trenkle, A., WertzLutz, A.E. Horse, R.L., Beitz, D.C., 2008. Use of 25hydroxyvitamin D3 and vitamin $\mathrm{E}$ to improve tenderness of beef from the longissimus dorsi of heifers. J. Animal Sci. 86, $1649-1657$.

[29] Namiki, M., 2007. Nutraceutical functions of sesame: a review. Crit. Rev. Food Sci. Nutr. 47, 651-672.

[30] Kang, M.H., Naito, M., Kawai, Y., Osawa, T., 1999. Antioxidative effects of dietary defatted sesame flour: in hypercholesterolemia rabbits. J.Nutr.129, 1111-1119.

[31] Kamiyama, M., Shibamoto, T., 2012. Flavonoids with potent antioxidant activity found in young green barley leaves. J. Agric. Food Chem. 60, 6260-6267. 